\title{
Germigny-des-Prés, un nouveau regard
}

\section{Christian Sapin}

\section{(2) OpenEdition}

\section{Journals}

\section{Édition électronique}

URL : https://journals.openedition.org/cem/16003

DOI : $10.4000 /$ cem. 16003

ISSN : 1954-3093

Éditeur

Centre d'études médiévales Saint-Germain d'Auxerre

\section{Référence électronique}

Christian Sapin, «Germigny-des-Prés, un nouveau regard », Bulletin du centre d'études médiévales d'Auxerre / BUCEMA [En ligne], Hors-série $n^{\circ} 11$ | 2019, mis en ligne le 09 avril 2019, consulté le 04 mars 2023. URL : http://journals.openedition.org/cem/16003; DOI : https://doi.org/10.4000/cem.16003

Ce document a été généré automatiquement le 4 mars 2023.

\section{(c) (i) (2) (2)}

Creative Commons - Attribution - Pas d'Utilisation Commerciale - Partage dans les Mêmes Conditions 4.0 International - CC BY-NC-SA 4.0

https://creativecommons.org/licenses/by-nc-sa/4.0/ 


\title{
Germigny-des-Prés, un nouveau regard
}

\author{
Christian Sapin
}

1 L'oratoire de l'évêque d'Orléans, construit dans les années 800, apparaît, pour certains, comme «la plus ancienne église de France», et, pour d'autres, comme une "recréation » typique des restaurateurs du XIX ${ }^{e}$ siècle. Quel que soit notre sentiment, cette construction ne peut laisser indifférent. L'image toujours en arrière-plan de la chapelle palatine d'Aix nous renvoie à une période où s'élaborent de nouvelles constructions savantes en pierre. Tandis qu'étaient réévaluées plusieurs constructions emblématiques de cette période en Europe - Aix-la-Chapelle, Lorsch, Müstair, ou Brescia par exemple - ou en France - Saint-Germain d'Auxerre, Saint-Philbert-deGrand-Lieu... -, il devenait nécessaire de faire le point des connaissances sur ce site, aussi bien à partir d'une lecture critique des sources, que d'un rappel développé de l'historiographie abondante de près de deux siècles, ou de travaux récents sur le monument.

2 Deux journées, les 10 et 11 juin 2016, n'étaient pas de trop pour cette réévaluation du dossier Germigny, afin de comprendre à quelle réalité s'attache véritablement ce site, à la lumière, notamment, de nouvelles méthodes d'investigation. L'idée de cette rencontre s'est trouvée renforcée avec les recherches récentes sur le verre et les mosaïques. La mosaïque de Germigny fait partie des «trésors» du haut Moyen Âge, tout en étant en France un unicum. Son intérêt a été mille fois souligné, surtout pour son iconographie, mais, ces dernières années, les progrès des analyses sur la technique du verre ou sur l'or des tesselles ont encouragé une nouvelle démarche sur les matériaux même de la mosaïque, qui reste au cœur de l'attrait pour ce monument. Cela a été en particulier le travail de Line Van Wersch, dont on lira les premières conclusions. Ce point départ nous a invité à reconsidérer l'ensemble, en faisant le point sur la construction, le décor, comme sur son prestigieux commanditaire, l'évêque Théodulf. Ces journées ont bénéficié, en outre, de l'approche d'historiens, qui se sont penchés récemment sur la production littéraire de l'évêque. 
3 La connaissance des sources propres au site ainsi que le dossier de restauration du monument a été considérablement renouvelée grâce au travail universitaire de Justine Croutelle. Nous la remercions ainsi que tous ceux qui ont répondu à notre demande, afin de reconsidérer les dossiers des inscriptions, du décor ou de la construction. Il reste beaucoup à faire, à la fois dans le traitement de la documentation retrouvée, comme ces dessins de Juste Lisch, conservés au musée d'Orsay, ou, plus encore, sur le terrain, avec la reprise de fouilles archéologiques aux abords de l'oratoire. Nous rappellerons, ici, les premières avancées des travaux de terrain en 1930 à l'occasion du Congrès archéologique. Mais, depuis, aucune recherche nouvelle n'a été entreprise et la prospection radar faite récemment ne peut qu'encourager de nouvelles initiatives, projetées dans les prochaines années.

4 Le point d'étape que constituent les deux journées d'études de 2016, ici publiées en ligne, ne pouvait que laisser de nombreuses questions ouvertes. La table ronde conclusive a ainsi ouvert d'autres pans à explorer, aussi bien sur le décor - origine de l'atelier des sculpteurs, diversité des modèles, relation avec l'atelier des stucateurs, place de l'atelier des mosaïstes entre les exemples germaniques et italiens, etc. - que sur le cadre économique et politique du site - recherches sur la constitution du domaine, sur l'environnement immédiat ou la construction d'une résidence toujours hypothétique. À l'issue de la table ronde, la dernière journée s'est prolongée dans et autour du monument, avec les habitants de la Communauté de communes et les visiteurs à travers des ateliers de discussions et de présentations de nos travaux, en trois endroits du site.

Outre cette publication, ces journées ont donné lieu, grâce à la DRAC Centre-Val de Loire, à l'édition d'une plaquette pour les visiteurs, rendant compte de nos travaux et permettant la visite du monument sous un autre regard. Aujourd'hui, observer plus profondément cette église, c'est, en effet, faire appel à l'histoire, à l'histoire de l'art, à l'archéologie, comme aux analyses physico-chimiques, et accepter une relecture critique des sources depuis le $\mathrm{IX}^{\mathrm{e}}$ siècle. Mais c'est aussi recourir aux techniques nouvelles d'investigation sur les maçonneries, le décor et même le sol à travers la magie du radar.

6 Ces journées n'auraient pu être organisées sans le soutien de nos partenaires belges Line Van Wersch, l'une des chevilles ouvrières du colloque, le FNRS et l'UC Louvain - et de la DRAC de la Région Centre-Val de Loire, auxquels nous adressons nos plus vifs remerciements. Toute notre gratitude va également à Sylvie Le Clech, sa directrice, qui, avec ses services et, en particulier, Sylvie Marchant, a été l'un des piliers, au côté du Cem d'Auxerre et de Corinne Lainé, de la préparation. Nous n'oublierions pas la commune de Germigny et son maire, Monsieur Thuiller, qui a été sur le pont à plusieurs reprises, ni la Communauté de communes du Val d'Or et Foret, ainsi que l'office du tourisme et Madame De Haro, qui ont pris une grande part à cette organisation. 


\section{AUTEUR}

\section{CHRISTIAN SAPIN}

Directeur de recherche émérite au CNRS, UMR Artehis 